\title{
Cmambu
}

\section{К ПРОБЛЕМЕ СООТНЕСЕНИЯ ОБЩИХ, СПЕЦИАЛЬНЫХ И ТВОРЧЕСКИХ СПОСОБНОСТЕЙ (НА ПРИМЕРЕ МАТЕМАТИЧЕСКОЙ ОДАРЕННОСТИ)}

\author{
Д.Б. БОГОЯВЛЕНСКАЯ ${ }^{\mathrm{a}}$ А.Н. НИЗОВЦОВА
}

\begin{abstract}
${ }^{a}$ ФГБНУ «Психологиеский институт РАО», 125009, Россия, Москва, ул. Моховая, д. 9, стр. 4
${ }^{\circ}$ Московский государственный университет имени М.В. Ломоносова, 119991, Россия, Москва, Ленинские горы, Ә. 1
\end{abstract}

\begin{abstract}
Резюме
В статье рассматривается проблема соотношения общих, специальных и творческих способностей. Представлен анализ теоретических позиций по проблеме общих и специальных способностей. Описана дискуссия между В.А. Крутецким и С.Л. Рубинштейном. Рубинштейн показал, что специальные способности фактически сводятся к общим. Окончательное решение этой проблемы было предложено В.Д. Шадриковым в теории способностей как свойств функциональных систем и специальных способностей как общих, приобретших свойство оперативности под влиянием требований деятельности; снимается наблюдаемое противоречие и однозначно решается вопрос о природе специальных способностей. Проблема соотношения общих и творческих способностей в данный момент особенно актуальна за рубежом (Б. Срираман, Д. Питта-Пантаци, М. Катту, Р. Лейкин и др.). В.Д. Шадриков рассматривает способности на трех уровнях: индивида (натуральные способности), субъекта деятельности (специальные способности) и личности (включая ее нравственную сферу). Способности на уровне личности и есть одаренность, которая может перерастать в творчество. Далее приводятся развиваемые нами в рамках процессуальнодеятельностного подхода С.Л. Рубинштейна представления о творческих способностях как способности к развитию деятельности по своей инициативе. Соотнесение различных видов способностей рассматривается нами на примере математической одаренности. В исследовании приняли участие студенты и выпускники математических специальностей (в том числе кандидаты наук) престижных российских вузов $(\mathrm{n}=83)$. Творческие способности и одаренность диагностируются с помощью методики, разработанной в рамках метода «Креативное поле» на математическом материале. Результаты сопоставляются с интеллектуальными и личностными методиками. Было показано, что в овладении математическим материалом реализуются общие способности. Определяющей для проявления творческих способностей и одаренности является познавательная направленность личности, которая выражается в развитии деятельности по своей инициативе.
\end{abstract}

Ключевые слова: общие способности, специальные способности, математические способности, одаренность, творчество, личность. 
Математическое творчество и математический ум не могут быть безотносительными к творчеству вообще и уму вообще.

Ж. Адамар

Сегодня в качестве государственной ставится задача выявления, развития и сопровождения детей с общей и специальной одаренностью. В настоящее время выявление одаренности проводится чаще всего на уровне здравого смысла: по успеваемости и победам в различных соревновательных мероприятиях. В связи с таким положением особо актуальным становится научно обоснованное определение одаренности.

Острее всего проблема соотношения и природы общих и специальных способностей была поставлена В.А. Крутецким. Монография В.А. Крутецкого «Психология математических способностей школьников» является фундаментом для всех проводимых в данной области исследований.

\section{Общие и специальные способности в структуре математической одаренности}

Проблема соотношения различных видов способностей, которая ставилась в отечественной психологии во второй половине ХХ в. (Рубинштейн, 1960; Крутецкий, 1968), в настоящий момент особенно актуальна в зарубежных исследованиях (например: Pitta-Pantazi et al., 2011, 2013; Kattou et al, 2013; Kontoyianni et al., 2013; Hong, Aqui, 2004).

По мнению P. Лекин (Leikin, Pitta-Pantazi, 2013), за последние полвека завершено лишь небольшое число систематических исследований, посвященных математической одаренности. Работы Крутецкого о математических способностях детей школьного возраста остаются уникальными в течение прошедших десятилетий.

В июле 2016 г. состоялся 13-й международный конгресс по математическому образованию. Основная тема конгресса - природа математической одаренности. В сборнике конгресса дается определение математической одаренности по В.А. Крутецкому (Singer et al., 2016, p. 3). Определение математического творчества Крутецкого также используют ряд современных авторов (Haylock, 1987; Sriraman et al., 2013; Kattou et al., 2013; Leikin, PittaPantazi, 2013; Mann, 2006).

В.А. Крутецкий в своих исследованиях отмечает следующие компоненты математических способностей: а) способность к логическому мышлению в сфере количественных и пространственных отношений; б) способность к быстрому и широкому обобщению математических объектов, отношений и действий; в) способность к свертыванию процесса математического рассуждения и системы соответствующих действий; г) гибкость мыслительных процессов в математической деятельности; д) стремление к ясности, простоте, экономности и рациональности решений; е) способность к быстрому переключению с прямого на обратный ход мысли.

Выделенная В.А. Крутецким способность к быстрому и широкому 
обобщению математических объектов, отношений и действий является одной из самых значимых в приведенной структуре математических способностей. Основываясь на анализе полученных им данных, В.А. Крутецкий делает вывод о специфичности данной способности для математической деятельности.

Вступая в дискуссию с В.А. Крутецким, С.Л. Рубинштейн пишет, что всякая операция (логическая, счетная, грамматическая, словообразования и словоизменения) всегда основывается на определенных отношениях, которые она реализует, поэтому обобщение этих отношений, а значит, и вычленение этих отношений, и их анализ - необходимое условие успешного функционирования операций, на них основываюшихся. Таков, по его мнению, вывод, к которому приводит теоретический анализ (Рубинштейн, 1960). Исследования С.Л. Рубинштейна показали, что мера свернутости мыслительных процессов является производным выражением соотношения обобщения и анализа: мыслительный процесс тем более свернут, чем в большей мере он оперирует уже сложившимися или быстро складывающимися обобщениями, снимающими необходимость анализа в некоторых звеньях; он тем более развернут, чем дольше человек посредством анализа идет к новым для него обобщениям. Таким образом, по данным этих исследований, второй показатель не выходит за пределы первого. С.Л. Рубинштейн также пишет, что и третий показатель В.А. Крутецкоголегкая обратимость отношений может быть сведен к первому.
Тем самым С.Л. Рубинштейн показывает, что выявленные В.А. Крутецким специфические компоненты математических способностей объяснимы с позиции его представления о структуре способностей: как наличия ядра, обеспечивающего работу периферии - сложившейся системы операций.

Опровергая критику С.Л. Рубинштейна, В.А. Крутецкий выдвигает гипотезу о том, что, помимо способности к свернутости психических процессов, «возможно, что и все остальные компоненты формируются на основе первоначально складываюшихся - способности к обобщению и математической направленности ума» (Крутецкий, 1968).

Феноменологическое описание данного явления - общая и специфическая способность одновременно - достаточно объективно. Хотя, по нашему мнению, это не продвигает нас в понимании природы и соотношения общих и специальных способностей.

Однако анализ научной литературы по математической одаренности и особенност ям математ ического мышления показывает, что математическая одаренность определяется с точки зрения индивидуальных способностей в математическом процессе, таких как: 1) способность к абстракции, обобщению и ви́дению математических структур (Kiesswetter, 1985; Sriraman, 2003); 2) способность управлять данными (Якиманская, 2004); 3) способность осваивать принципы логического мышления и заключения (Goldberg, Suppes, 1972); 4) способность думать по аналогии и эвристически, ставить проблемы 
(Kiesswetter, 1985); 5) интуитивное осознание математического доказательства (Sriraman, 2004); 6) независимое открытие математических принципов (Ibid); 7) способность визуализировать проблемы и отношения (Hershkowitz, 1989). Перечень этих характеристик математических способностей указывает на отсутствие в приведенных исследованиях учета критического анализа данной позиции, проведенного С.Л. Рубинштейном (1960) и В.Д. Шадриковым (2006, 2010).

Обосновывая в конце своей книги (Крутецкий, 1968) положение о специфичности способностей, В.А. Крутецкий пишет о своеобразии и особенностях мира математики. Математик постоянно сталкивается с пространственными и количественными отношениями, выраженными посредством числовой и знаковой символики, мыслит ими, комбинирует, оперирует. В условиях этой специфической деятельности общая способность, как считает В.А. Крутецкий, трансформируется и выступает как специальная.

Включение в определение математических способностей пространственного мышления характерно и для зарубежных авторов (PittaPantazi et al., 2013; Kattou et al., 2013; Cipora et al., 2016; Leikin, PittaPantazi et al., 2013; Demetriou et al., 2002). Высказывания самих математиков как бы подтверждают данное мнение Крутецкого, когда на первое место в математических способностях ставится способность к абстракции, обобщению и ви́дению математических структур (Kiesswetter, 1985; Sriraman, 2003). Так, Ж. Адамар указывает на то, что математическое исследование принуждает его строить пространственную схему «для того, чтобы единым взглядом охватить все элементы рассуждения, чтобы их объединить в одно целое наконец, чтобы достичь... синтеза» (Адамар, 1970).

На самом деле в рамках школы С.Л. Рубинштейна было экспериментально доказано, что упоминаемая Ж. Адамаром схема является необходимым звеном любого мыслительного процесса. Процесс мышления при решении проблемной ситуации проходит ряд этапов, для которых характерен свой язык, свой код. Это позволяет осуществить схематическое построение системы отношений в данной проблемной ситуации, с чем и связано ее понимание. Это действительно, как говорил И. Гете, «видящая мысль». Мы рассматривали его как закономерный результат развития мышления, необходимый момент в процессе, предшествуюшем инсайту (Богоявленская, 2009). С.Л. Рубинштейн расценил это как доказанное экспериментально преодоление гештальтпсихологии в рассмотрении природы инсайта.

Следующий шаг в теории данного вопроса, сделанный В.Д. Шадриковым, превращает проблему соотнесения общих и специальных способностей, наконец, в прозрачную и непротиворечивую. Рассмотрение способностей В.Д. Шадриковым как свойств функциональных систем, реализующих отдельные психические функции, которые имеют индивидуальную меру выраженности, проявляющуюся в успешности и качественном своеобразии освоения деятельности, и специальных способностей как общих, приобретших 
свойство оперативности под влиянием требований деятельности (Шадриков, 2006), снимает наблюдаемое противоречие и однозначно решает проблему природы специальных способностей.

Творческие способности. Вместе с тем решение проблемы соотнесения разного типа способностей усложняется сопоставлением с творческими способностями, приобретающими все более важное значение под влиянием потребностей развития экономики.

Знаменательно название статьи Б. Срирамана (Sriraman, 2005) «Одаренность и креативность синонимы в математике?» («Are giftedness and creativity synonyms in mathematics?»), таким образом ставится вопрос о потребности четкого раскрытия природы этих понятий.

Как попытка ответа на данный вопрос предлагается модель способностей Д. Питты-Пантаци и др., которая рассматривается авторами как инновационная. Данная модель представляет интеграцию когнитивных (флюидного интеллекта, рабочей памяти, скорости контроля переработки информации), творческих и математических способностей, ведущих к новой концептуализации понятия математической одаренности (Pitta-Pantazi et al., 2011).

По мнению авторов, математическая одаренность состоит из математических способностей, математической креативности и когнитивных способностей. Согласно полученным данным, на построение математической одаренности математические способности влияют больше, чем математическая креативность. Как продолжение данного направления исследований можно рассматривать исследование М. Катту с соавт. (Kattou et al., 2013), которые выявили положительную корреляцию между математической креативностью и математическими способностями. Кроме того, конфирматорный факторный анализ показал, что математическая креативность является подкомпонентом математических способностей. В конечном счете математическая одаренность опять сводится к математическим способностям. Вместе с тем приведенные работы и модель интеграции способностей отражают общую тенденцию научного поиска.

Продвижением в решении данной проблемы является последний цикл работ В.Д. Шадрикова (Шадриков, 2006, 2010). При рассмотрении проблем профессиональных способностей он делает следующий шаг в определении теперь уже творческих способностей.

В.Д. Шадриков рассматривает способности на трех уровнях реализации: индивида (натуральные способности), субъекта деятельности (специальные способности) и личности (включая ее нравственную сферу). Выделению уровня личности предшествовала разработка им в качестве научного руководителя «Рабочей концепции одаренности» (1998-2003), в которой одаренность как способность к творчеству рассматривалась в качестве системного качества, интегрирующего когнитивную и личностную сферу ребенка. Наличие способностей уровня личности принципиально противоположно креативному блоку в модели Д. Питты-Пантаци. Согласно В.Д. Шадрикову, способности на 
уровне личности, включающие ее нравственность, и есть одаренность, которая может перерастать в творчество (в том случае, если в структуре личности доминируют познавательная потребность и духовные ценности).

В раскрытии природы творческих способностей для нас принципиальной была позиция Ж. Адамара, рефлексирующего процессы открытий в области математики. Вслед за Э. Клапередом он утверждал, что существует два вида изобретений. Первый характеризуется тем, что «цель известна, и нужно найти средства, чтобы ее достигнуть, так что ум идет от вопроса к решению... Второй же, напротив, состоит в том, чтобы открыть факт и затем представить себе, чему он может служить... Как это ни кажется парадоксальным, чаще всего встречается второй вид изобретений, и он становится все более обшим по мере развития науки» (Адамар, 1970, с. 116). Фактически здесь Ж. Адамар говорит о феномене творчества как действия, теряющего форму ответа (действие не как ответ на вопрос).

И далее Ж. Адамар приводит многочисленные примеры и окончательно приходит к выводу, что редко (или почти никогда) важные математические исследования проводились непосредственно с целью их определенного практического применения. «Чаще всего исследователи руководствовались общим мотивом всякой научной работы - желанием знать и понимать. Следовательно, из двух названных видов изобретений математикам известен только второй» (Там же). Таким образом, решающим фактором открытий без внешнего стимула является мотив познания самого субъекта.

\section{Эмпирическое исследование}

Цель исследования - анализ соотношения общих, специальных и творческих способностей на примере математической одаренности.

\section{Гипотезь исследования}

1. Математические способности являются проявлением общих способностей, приобретших свойство оперативности под влиянием требований деятельности.

2. Математическая одаренность является системным качеством, интегрирующим личностные и когнитивные компоненты при доминировании познавательной потребности в структуре личности.

\section{методикu}

Рассмотрение творческих способностей на уровне способностей личности (по В.Д. Шадрикову) ставит вопрос о методиках их диагностики. Вместе с тем имеющиеся диагностические процедуры ограничиваются фиксацией, по словам Ж. Адамара, старого типа творчества - решением поставленных задач. В проблемной ситуации движение мысли, с одной стороны, стимулировано ее требованием, но, с другой, ограничено, находясь как бы в прокрустовом ложе между ее условиями и требованием. Hе решают эту проблему тесты интеллекта и креативности, которые не улавливают роли самой личности, ее нравственности (Богоявленская, 2009). Чтобы в реальные сроки 
выявить присущий личности потенциал, необходимо обеспечить наличие области, пространства для прослеживания хода мысли за пределами решения исходной задачи, чтобы моделировать реальную познавательную ситуацию. Этим требованиям отвечает метод «Креативное поле» (Там же).

Для диагностики общих умственных способностей использовался тест Дж. Равена. Специальные способности оценивались по успешности овладения математическим материалом (в рамках первого, заданного слоя) методики «Система координат», разработанной в рамках метода «Креативное поле».

Учитывая сложившуюся традицию, для диагностики творческих способностей как отдельного вида способностей мы использовали тест П. Торренса.

Понимание одаренности как системного качества включает, помимо интеллектуальных, диагностику личностных компонентов, для этого нами использовались тест мотивационной структуры личности В.Э. Мильмана и методика мировоззренческой активности личности Д.А. Леонтьева и А.Н. Ильченко.

Метод «Креативное поле» (Богоявленская, 1971, 1983, 2002, 2009) позволяет вычленить «в чистом виде» такую особенность личности, как интеллектуальная активность (ИА) - развитие деятельности по собственной инициативе. Метод предполагает многократный индивидуальный эксперимент по решению однотипных задач, совокупность которых имеет двухслойную структуру. Первый, поверхностный слой - заданная деятельность по решению конкретных задач. Второй - глубинный слой, замаскированный «внешним» слоем и неочевидный для испытуемого, - это деятельность по выявлению скрытых закономерностей, открытие которых не требуется для их решения.

Валидность метода «Креативное поле» доказана экспериментально в течение 48 лет на более 9 тыс. испытуемых: свыше 7 тыс. учашихся 48 школ разных регионов страны с I по XI класс и дошкольников, а также свыше 2 тыс. взрослых профессий широкого спектра. Его прогностичность проверена в лонгитюдах длительностью от 6 до 34 лет. При сопоставлении результатов диагностики по методу с критериями профессиональной успешности в разных группах коэффициенты корреляции колеблются от 0.73 до 0.96. При сопоставлении методик на различном материале («Цилиндрические шахматы», «Система координат» и др.) коэффициенты корреляции колеблются от 0.65 до 0.87 .

В рамках метода «Креативное поле» была разработана методика «Система координат» (Богоявленская, 1983; Петухова, 1976), которая построена на специфическом математическом материале. В первую очередь, она была предназначена для проверки предположений о преимуществе профессионального образования для проявления творческих способностей. Анализ творческих способностей испытуемых с математическим образованием в предшествующих исследованиях их не подтвердил (Богоявленская, 2009).

Принципиальная схема методики состоит в том, что испытуемый должен расположить в заданной системе 
координат предлагаемые числа, координаты которых он может вычислить по формулам, составленным заранее и написанным на карточках. Система формул была разработана в дипломной работе М. Байзеля и впервые апробирована в диссертационном исследовании И.А. Петуховой. В соответствии с основными принципами метода «Креативное поле» работа с одним испытуемым проходит в течение нескольких встреч. Ему предлагаются для решения по очереди 9 задач (в каждой задаче 9 чисел). Порядок предъявления чисел внутри задач случайным образом перемешан. Каждый испытуемый получает одну и ту же итоговую случайную последовательность. Эксперт оценивает правильность каждого ответа, отмечает время решения и фиксирует результаты анализа деятельности испытуемого, выходящие за пределы требований предъявляемой задачи.

Если испытуемый прочно овладевает предложенной ему деятельностью, находит оптимальный способ решения, но не выходит за пределы решения с его помощью предъявляемых задач, то мы его относим к стимульно-продуктивному уровню (см. рисунок 1). Если в процессе решения задач испытуемый начинает анализ всей системы по своей инициативе и находит новые закономерности, то мы относим его к эвристическому уровню (см. рисунок 2). На этом уровне выделяются два типа эвристик - формульные и содержательные. Формульными эвристиками называют те, которые присутствуют в формулах предъявляемых условий либо непосредственно вытекают из них. Содержательнье эвристики заключаются в закономерностях цифр на поле координат. Формульные эвристики считаются менее ценными, поскольку специалисты в области математики имеют большой опыт работы с уравнениями. Содержательные же эвристики максимально освобождены от влияния предыдущего опыта испытуемых. Также выделяется переходный уровень (см. рисунок 3), сюда относятся частные и наглядные эвристики, обнаружение которых еще не может

Стимульно-продуктивный уровень вьполнения задания

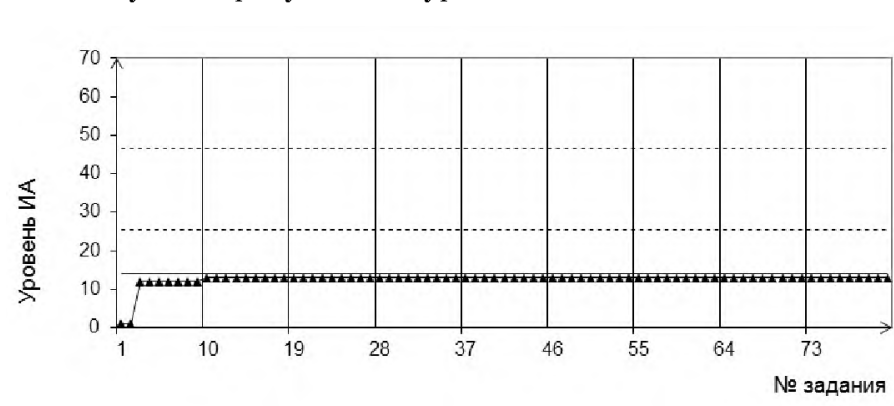

Рисунок 1

—птимальное решение
-..-- Граница между различными уровнями эвристик
^ Стимульно-продуитивный и переходный уровни 
Рисунок 2

Эвристический уровень выполнения задания

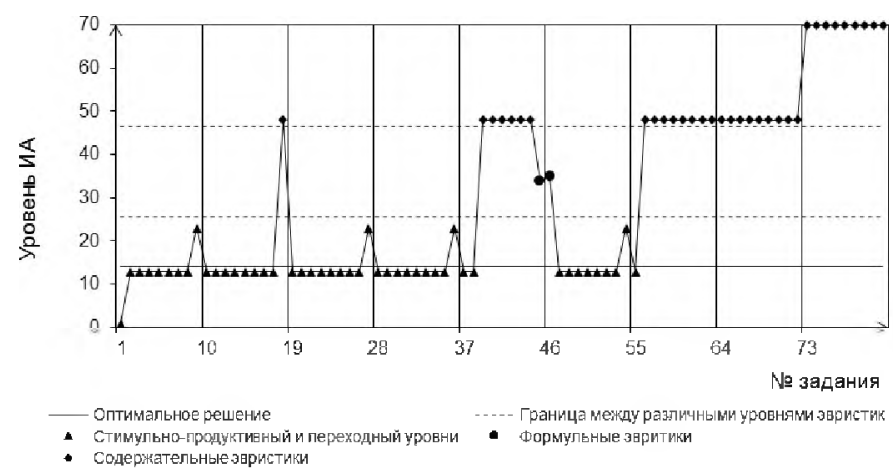

Pисунок 3

Переходный уровень выполнения задания

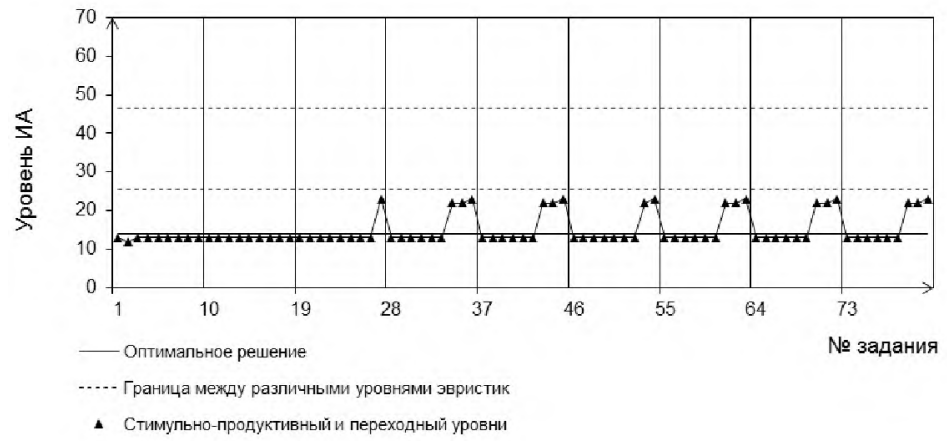

свидетельствовать о выходе на эвристический уровень. Креативный уровень (см. рисунок 4) связан с теоретическим обоснованием самостоятельно найденных закономерностей.

На рисунках отражен ход решения испытуемыми заданий с № 1 по № 81, номера заданий отмечены на оси $x$. На оси $y$ отмечены баллы, отражающие высоту/сложность использованной в каждом задании эвристики. Все когдалибо обнаруженные решения были проранжированы экспертами (психологами и математиками) по степени их глубины, обобшенности, сложно- сти и отнесены к различным уровням ИА. Решение испытуемого по каждому заданию сопоставляется с этим проранжированным списком, и решению присуждается соответствующий балл.

Существуют основные показатели:

- медиана ИА - медиана баллов решений по всем заданиям (обычно испытуемым выполняется 81 задание), позволяет оценить усредненную сложность/обобщенность открытых закономерностей;

- максимум ИА - эвристика, получившая наивысший балл в ходе решений заданий; 
Креативный уровень выполнения задания

Рисунок 4

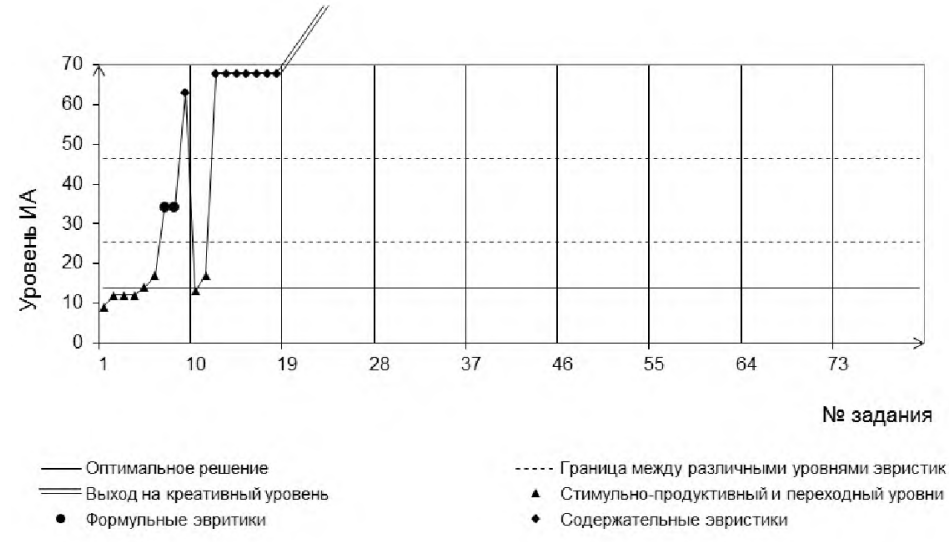

- среднее время по всем заданиям;

- максимальное время по всем задачам (как правило, дольше всего испытуемые решают первую задачу, соответственно максимальное время возможно рассматривать как один из показателей обучаемости).

Продвинутье прогрессивные матрицы Дж. Равена (2002). Невербальный тест диагностики интеллекта был разработан с целью более тонкой дифференциации в тех случаях, когда способности испытуемых выше среднего уровня. Тест представляет собой две серии, в первой - 12 заданий, во второй - 36 заданий. В нашем исследовании использовался вариант с 40-минутным ограничением по времени.

Фигурная форма теста твориеского мыиления П. Торренса в адаптации Е.И. Щеблановой (Щебланова и др., 1993). Фигурная форма состоит из трех субтестов: «Нарисуйте картинку», «Завершение фигуры», «Повторяющиеся линии». В рамках этого метода выделяют ряд показате- лей: беглость (количество завершенных фигур), гибкость (количество использованных категорий), оригинальность (способность выдвигать необычные идеи), разработанность (способность обогощать идеи дополнительными деталями).

Диагностика мотивационной структурь личности, вариант для взрослых (Мильман, 2005). Методика включает 14 утверждений, касаюшихся жизненных стремлений и образа жизни испытуемых. На каждое из утверждений приходится 8 вариантов ответов, с которыми необходимо выразить свою степень согласия. Данная методика имеет проверочную шкалу: в ряде пунктов, по которым существует вероятность для испытуемого приукрасить свой портрет, есть просьба уточнить свой ответ конкретными данными. В.Э. Мильман выделяет следующие мотивационные шкалы, отражающие основные направленности личности: П мотивация поддержания жизнеобеспечения, К - мотивы комфорта и безопасности, С - статусно-пре- 
стижная мотивация, О - мотивация общения, Д - мотивация общей активности, ДР - мотивация творческой активности, ОД - мотивация принести общественную пользу.

Для полноты диагностики общей мотивационной сферы личности каждая из семи мотивационных шкал подразделяется на 4 подшкалы: общежитейская, т.е. относящаяся ко всей сфере жизнедеятельности; рабочая (учебная) - относится к сугубо рабочей или учебной сфере; «идеальное» состояние мотива, т.е. уровень собственно побуждения, устремления; «реальное» состояние, т.е. насколько испытуемый расценивает данный мотив удовлетворенным в настоящее время, а также то, сколько им для этого затрачивается усилий. Согласно инструкции В.Э. Мильмана, показатели одноименных шкал (идеальная-житейская и идеальнаярабочая, реальная-житейская и реальная-рабочая) можно складывать. Мы в нашем исследовании сгруппировали данные в две шкалы - идеальную и реальную.

Методика мировоззренческой активности (Леонтьев, Ильченко, 2007) представляет собой 13 пар утверждений, касающихся различных сторон жизни человека. Каждая пара имела общее начало и заканчивалась раздваивающимися вариантами окончания (А и Б).

Испытуемому предлагалось оценить степень своего согласия с каждым из двух предложенных вариантов окончания утверждений в процентах - от 0 до $100 \% \quad(0 \%-$ абсолютно не согласен с утверждением, $100 \%$ - полностью согласен). В инструкции оговаривалось, что сумма не обязательно должна быть равна 100\%. Испытуемый также мог предложить свой вариант ответа, если его не устраивали предложенные формулировки.

В итоге возможны четыре типа ответов:

1) однозначный $(A=100 \%, Б=$ $=0 \%$ либо наоборот);

2) сочетание $(A+B \leqslant 100 \%)$;

3) пересечение $(\mathrm{A}+\mathrm{B}>100 \%)$;

4) самостоятельный ответ.

\section{Испьтуемье}

В исследовании, проводившемся с 2011 по 2016 г., приняли участие 83 человека, 57 мужчин и 26 женщин в возрасте от 18 до 34 лет $(\mathrm{M}=23.352$, $\sigma=2.822$ ), это 38 студентов математических специальностей московских вузов (МГУ, МФТИ, МИФИ, МГТУ им. Н.Э. Баумана), 12 аспирантов, 33 работающих по специальности выпускника, в том числе 7 кандидатов физико-математических наук (научные сотрудники указанных вузов и математических институтов РАН).

Работа с испытуемыми проходила в формате индивидуальных встреч, только на выполнение методики «Система координат» и проведение интервью необходимо от двух до четырех встреч в среднем по 1.5 часа. Выполнение тестов Дж. Равена, П. Торренса, В.Э. Мильмана, Д.А. Леонтьева проходило в определенный день индивидуально или в минигруппах.

\section{Результаты}

Результаты, полученные в ходе диагностики по методике «Система координат», представлены в таблице 1. 
Полученные данные (см. таблицу 1) по общему распределению испытуемых по уровням ИА буквально воспроизводят статистические данные предшествующих 40 лет: независимо от профессиональной принадлежности число эвристов не превышало $20 \%$, а креативов было менее $5 \%$.

В исследовании мы сопоставили результаты по остальным методикам в двух группах - стимульно-продуктивного уровня ИА (куда также включены испытуемые переходного уровня) и эвристического (куда также включены испытуемые креативного уровня в связи с малочисленностью последних).

\section{Сопоставление методики}

«Система координат» $u$

Продвинутых прогрессивных матрии Дж. Равена

Получены положительные корреляции Спирмена между результатами теста Дж. Равена и: медианой ИА $\left(r_{s}=0.316, p=0.008\right)$, максимальной эвристикой $\left(r_{s}=0.393, p=0.001\right)$, средним временем по «Системе координат» $\left(r_{s}=-0.465, p=0.000\right)$, максимальным временем «Системе координат» $\left(r_{s}=-0.433, p=0.000\right)$.

Успешное овладение деятельностью в рамках метода «Креативное поле» является также диагностикой интеллектуальных способностей обследуемого, одним из возможных показателей здесь могут быть время, которое было затрачено на решение задач, тип и число ошибок. Группа испытуемых стимульно-продуктивного уровня неоднородна. Среди них есть как те, кто с трудом нашел оптимальное решение, дальнейшее развитие деятельности по своей инициативе для них затруднено ввиду невысоких способностей, так и те, кто, быстро освоив систему требований, довольствуются лишь виртуозным исполнением заданной деятельности.

При исключении испытуемых стимульно-продуктивного уровня, набравших низкие баллы по тесту Дж. Равена (общий балл менее 40), различия между оставшимися и эвристами, согласно критерию Манна-Уитни, нивелируются ( $\mathrm{U}=236$, $Z=-1.627, p=0.104)$, какие-либо корреляции между методиками не обнаруживаются. Соответственно считать высокие показатели по тестам интеллекта достаточным критерием для выявления одаренности было бы неправильно.

\section{Сопоставление методики}

«Система координат» и Tеста творческого мышления П. Торренса

Корреляционный анализ какихлибо связей между показателями

Таблица 1

Распределение по уровням интеллектуальной активности

\begin{tabular}{|c|c|c|c|c|c|}
\hline & \multicolumn{4}{|c|}{ Уровень ИА } & \multirow{2}{*}{ Всего } \\
\cline { 2 - 5 } & $\begin{array}{c}\text { Стимульно- } \\
\text { продуктивный }\end{array}$ & Переходный & Эвристический & Креативный & \\
\hline \multirow{2}{*}{ Испытуемые } & 53 & 9 & 18 & 3 & 83 \\
\cline { 2 - 5 } & $63.9 \%$ & $10.8 \%$ & $21.7 \%$ & $3.6 \%$ & $100.0 \%$ \\
\hline
\end{tabular}


методик «Система координат» и теста П. Торренса не выявил, что является отчасти предсказуемым результатом. Согласно исследованиям Д.Б. Богоявленской, креативность эвристов основана на глубоком анализе и переосмыслении заданных условий, поэтому в случае, если эвристы набирают высокий балл по оригинальности, механизм этого явления носит принципиально другой характер.

Среди приемов, которыми пользовались обе группы испытуемых, можно выделить: вид сверху, переворот заданного стимула, использование перспективы, необычный ракурс рисунка. Последний прием, согласно критерию Манна-Уитни, встречался чаше у эвристов ( $\mathrm{U}=326, \mathrm{Z}=-1.968$, $p=0.049)$. Также эвристы чаще получали премию за объединение стимульных фигур ( $\mathrm{U}=306, \mathrm{Z}=-2.277$, $p=0.023)$.

Качественные различия работы испытуемых разного уровня можно проиллюстрировать на примере одного из самых ярких эвристов, набравшего высокий балл за оригинальность. Он часто переворачивал заданные стимульные фигуры, использовал их не как основную составляющую рисунка, а как периферическую деталь или соединительный элемент между частями картины. А испытуемый креативного уровня (геометр по специальности) трактовал заданный стимул как относящийся к разным плоскостям, использовал стимул одновременно как часть разных объектов, создавал объемные изображения, учитывал законы перспективы.

Таким образом, при качественном рассмотрении рисунков можно сде- лать вывод, что оригинальные ответы эвристов в значительной степени объясняются применением профессиональных приемов. Следовательно, за показателем оригинальности в данном случае не стоит творческий процесс.

\section{Сопоставление методики «Система координат» $u$ Диагностического теста мотивационной структуры личности В.Э. Мильмана}

В идеальном плане испытуемые из групп эвристов и стимульных показали схожие результаты. Единственное различие было в мотивации комфорта и безопасности. Согласно критерию Манна-Уитни, в идеальном плане для испытуемых эвристического уровня мотивация комфорта (К) играет меньшую роль, чем для испытуемых стимульного-продуктивного уровня $(\mathrm{U}=265, \mathrm{Z}=-2.238$, $p=0.025$ ).

Подтверждение тому, что в «идеальном плане» мотивация комфорта и безопасности имеет для испытуемых эвристического уровня меньшее значение, можно найти в ответе испытуемой № 21 (эврист); «Если он математик из России, значит, он очень любит математику и готов работать бесплатно в условиях, в которых невозможно работать. Без денег, без нормальных конференций, без нормальных публикаций. Ради чистой науки. Таких у нас мало. Я считаю, что почти нет».

Основные различия можно увидеть в «реальной» мотивации испытуемых. Так, испытуемые эвристичекого и стимульного-продуктивного уровней, согласно критерию Манна- 
Уитни, различаются по мотивации общей активности Д ( $\mathrm{U}=244, \mathrm{Z}=$ $=-2.555, p=0.011)$ и мотивации творческой активности ДР (U $=240.5$, $\mathrm{Z}=-2.607, p=0.009)$, у эвристов оба этих показателя более высокие. В ответах на открытые вопросы теста В.Э. Мильмана испытуемые приводят реальные ответы на основании собственного опыта, подтверждающие выбор по данным шкалам. Например, испытуемый № 14 (эврист) стал самым молодым членом жюри заключительного этапа Bceроссийской олимпиады школьников по математике. Испытуемый № 15 (эврист) ныне председатель Оргкомитета турнира городов по Москве, один из трех членов Центрального оргкомитета с решающим голосом. Оба отмечают, что никогда не стремились к каким-то высоким должностям, просто в школе они активно участвовали в олимпиадах, во время обучения на механико-математическом факультете МГУ преподавали в предметных лагерях для школьников и помогали c организацией олимпиад, а после окончания вуза их увлечение вышло на более серьезный уровень. Оба этих испытуемых были диагностиро- ваны как эвристы, когда они были еще студентами III и IV курсов соответственно, А вот испытуемый № 83 (стимульно-продуктивный) свой выбор творческой деятельности аргументирует следующим образом: «В любом случае выполняешь творческую работу, иная плохо оплачивается».

\section{Результать сопоставления методики «Система координат» $u$ методики мировоззренческой активности}

Данные, полученные по методике, были перекодированы в четыре возможных типа ответа (см. таблицу 2).

В результате было получено неодинаковое количество разных типов ответов. Ответов однозначного типа оказалось $11.2 \%(\mathrm{~A}=100 \%, \mathrm{~b}=$ $0 \%$ либо наоборот), сочетание двух вариантов - 52.6\% (A + Б $\leqslant 100 \%)$, пересечение $(\mathrm{A}+\mathrm{B}>100 \%)-16.5 \%$ и самостоятельных ответов - 19.7\%.

Согласно критерию согласия Пирсона, испытуемые стимульнопродуктивного и эвристического уровней значимо различались по распределению частот различных типов ответов $\left(\chi^{2}=13.98, \mathrm{df}=3, p=0.003\right)$.

Таблица 2

Таблицы частот различных ответов по методике мировоззренческой активности

\begin{tabular}{|l|c|c|c|c|}
\hline & $\begin{array}{c}\text { Однозначный } \\
\text { ответ (1) }\end{array}$ & $\begin{array}{c}\text { Сочетание } \\
\mathbf{( 2 )}\end{array}$ & $\begin{array}{c}\text { Пересечение } \\
\mathbf{( 3 )}\end{array}$ & $\begin{array}{c}\text { Самостоятельный } \\
\text { ответ (4) }\end{array}$ \\
\hline $\begin{array}{l}\text { Стимульно- } \\
\text { продуктивный }\end{array}$ & 71 & 314 & 94 & 93 \\
\hline $\begin{array}{l}\text { Эвристический и } \\
\text { креативный }\end{array}$ & 19 & 110 & 39 & 66 \\
\hline Всего & 90 & 424 & 133 & 159 \\
\hline$\%$ & 11.17 & 52.61 & 16.50 & 19.73 \\
\hline
\end{tabular}


По результатам анализа с использованием коэффициента корреляции Спирмена (см. таблицу 3) были установлены связи частоты встречаемости самостоятельного ответа с медианой ИА $\left(r_{s}=0.296, p=0.015\right)$ и максимальной эвристикой ИА $\left(r_{s}=\right.$ $=0.350, p=0.005)$ (см. таблицу 3). Также была обнаружена обратная связь между медианой ИА и частотой первого ответа $\left(r_{s}=-0.251, p=0.049\right)$.

\section{Обсуждение результатов}

Bce наши испытуемые имеют математическое образование, они успешны в своей деятельности. Однако эвристов (даже обучающихся на младших курсах) характеризуют как одаренных студентов и талантливых преподавателей. Именно к ним как людям, не только знающим, но удивительно глубоко понимающим, обращаются за любой помощью студенты и коллеги. Среди испытуемых стимульно-продуктивного уровня, блестяще освоивших материал, есть те, кто добился больших успехов, как правило, в бизнесе, банковской системе и т.д.

Полученная корреляция между показателями по методике на математическом материале «Система координат» и результатами теста невербального интеллекта Дж. Равена позволяет сделать вывод о том, что успешное овладение математической деятельностью не является специальной способностью, а отражает общий уровень умственных способностей. При этом важно понимать, что группа испытуемых стимульнопродуктивного уровня неоднородна. Среди них есть те, кто с трудом нашел оптимальное решение, дальнейшее развитие деятельности по своей инициативе для них затруднено ввиду невысоких способностей, и те, кто, быстро освоив систему требований, довольствуются лишь виртуозным исполнением заданной деятельности. При исключении испытуемых стимульно-продуктивного уровня, набравших низкие баллы,

Таблица 3

Матрица интеркорреляций методик «Система координат» и мировоззренческой активности

\begin{tabular}{|c|c|c|c|c|c|}
\hline & 2 & 3 & 4 & 5 & 6 \\
\hline 1. Медиана ИА & $0.648^{* * *}$ & $-0.251^{*}$ & -0.211 & 0.15 & $0.296^{*}$ \\
\hline 2. Максимальная әвристика ИА & 1 & -0.186 & -0.228 & 0.028 & $0.350^{* *}$ \\
\hline 3. Однозначный (А или Б) & & 1 & -0.08 & -0.041 & $-0.299 *$ \\
\hline 4. Сочетание $(\mathrm{A}+\mathrm{B} \leqslant 100 \%)$ & & & 1 & $-0.546 * * *$ & $-0.654^{* * *}$ \\
\hline $\begin{array}{l}\text { 5. Пересечение (А+Б > 100\%) } \\
\text { Мировоззренческая } \\
\text { многомерность }\end{array}$ & & & & 1 & -0.044 \\
\hline $\begin{array}{l}\text { 6. Самостоятельный ответ } \\
\text { Мировоззренческая инициатива }\end{array}$ & & & & & 1 \\
\hline
\end{tabular}

\footnotetext{
${ }^{*} p<0.05,{ }^{* *} p<0.01,{ }^{* * *} p<0.001$.
} 
различия с эвристами нивелируются. Соответственно считать высокие показатели по тестам интеллекта достаточным критерием для выявления одаренности было бы неправильно.

Отсутствие каких-либо связей между методикой «Система координат» и Теста творческого мышления П. Торренса в очередной раз подтверждает несостоятельность и невалидность подхода диагностики одаренности по результатам дивергентной продуктивности. В нашей работе мы обнаружили, что испытуемые набирают высокие баллы по оригинальности за счет применения приемов, связанных с их профессиональной деятельностью. Таким образом, за показателем оригинальности в данном случае не стоит творческий процесс.

Диагностическая методика Мильмана показала, что мотивационная сфера испытуемых двух групп носит принципиально разный характер. В «идеальном» плане (желания, побуждения, устремления) обследуемые демонстрируют практически одинаковые результаты, единственным отличием было то, что для эвристов мотивация комфорта и безопасности имеет меньшее значение. А в «реальном» плане (насколько испытуемые действительно затрачивают усилия для реализации своих мотивов) мы обнаружили, что для эвристов мотивация общей и творческой активности имеет гораздо большее значение. Мотивация общей активности отражает энергичность, стремление субъекта приложить свои усилия и умения в той или иной сфере деятельности. Мотивация творческой активности включает созидание, понимание, познание. Эти результаты находят подтверждение в реальных достижениях эвристов нашей выборки.

Направленность личности на развитие деятельности по своей инициативе связана с мировоззренческой активностью. Это проявляется как в работе на знакомом математическом материале, так и в решении вопросов философского характера.

В нашем исследовании в группе профессиональных математиков были выявлены лица, у которых доминирует познавательная направленность личности, выражаемая в развитии деятельности по своей инициативе, что идентифицирует одаренность. Таким образом, творческие способности являются не отдельным видом способностей, а результатом структуры личности, где доминирует познавательная направленность.

\section{Выводы}

Проведенное исследование своей целью ставило определение соотношения трех видов способностей: общих, специальных и творческих. Было поставлено под сомнение существование специальных (в данном случае математических) и творческих как отдельных видов способностей.

В исследовании принимали участие студенты и выпускники математических факультетов ведущих вузов Москвы. В выборку не были включены испытуемые, у которых наблюдались трудности в овладении новой деятельностью, а также те, кто имел показатели тестов на интеллект ниже средних по выборке.

Было показано, что при фактически одинаково высоком уровне интеллектуальных показателей ис- 
пытуемые как эвристического, так и стимульно-продуктивного типа были в равной степени успешны в овладении математическим материалом.

Результаты исследования указывают на справедливость критики С.Л. Рубинштейном теории В.А. Крутецкого, рассматривающего математические способности как особые способности, и согласуются с теорией способностей В.Д. Шадрикова, в которой общие способности рассмат риваются как свойства функциональных систем, а специальные - как общие, приобретшие свойство оперативности под влиянием требований деятельности. Для нашего исследования были привлечены испытуемые, специализирующиеся в области математики, поскольку они владеют всеми операциями, необходимыми для решения математических задач. Сопоставление результатов методики на математическом материале с тестом на общие умственные способности показало, что успешное овладение математической деятельностью связано с общим уровнем умственных способностей. Таким образом, наш подход позволяет рассматривать природу специальных способностей как способностей уже не на уровне индивида, а на уровне субъекта деятельности (в данном контексте субъект деятельности рассматривается как ее исполнитель, а не как автор).

Потенциальное присутствие второго слоя, который открывали наши испытуемые с математическим обра- зованием в предлагаемой методике на математическом материале, характерно для любой деятельности. Испытуемые эвристического и креативного уровней, проявившие способность к развитию деятельности, что рассматривается нами как проявление творческих способностей, в отличие от испытуемых стимульно-продуктивного уровня, характеризовались «приверженностью» (по Ф. Гальтону) выбранной ими профессии. Они проявили способности на уровне личности (по В.Д. Шадрикову). В исследовании было показано, что одаренность (в частности, математическая) связана с высокой мировоззренческой активностью, а также мотивацией «обшей и творческой активности в реальном плане». Это нашло подтверждение в профессиональных достижениях испытуемых и в том, как их характеризовали окружающие.

Таким образом, проблема соотношения общих, специальных и творческих способностей решается в предложенном В.Д. Шадриковым уровневом рассмотрении способностей: на уровне индивида как общих; их реализация - на уровне субъекта труда как специальных; на уровне личности как творческих при доминировании в структуре личности духовных ценностей (в частности, познавательной направленности). Следовательно, было подтверждено наше понимание одаренности как способности к проявлению творчества; раскрыта роль когнитивных и личностных компонентов в ее структуре.

\section{Литература}

Адамар, Ж. (1970). Исследование психологии процесса изобретения в области математики. М.: Советское радио. 
Богоявленская, Д. Б. (1971). Метод исследования уровней интеллектуальной активности. Вопросы психологии, 1, 144-146.

Богоявленская, Д. Б. (1983). Интеллектуальная активность как проблема твориества. Ростовна-Дону: Изд-во Ростовского университета.

Богоявленская, Д. Б. (2002). Психология твориеских способностей. М.: ИЦ «Академия».

Богоявленская, Д. Б. (2009). Психология твориеских способностей. Самара: ИД «Федоров».

Крутецкий, В. А. (1968). Психология математических способностей икольников М.: Просвещение.

Леонтьев, Д. А., Ильченко, А. Н. (2007). Уровни мировоззренческой активности и их диагностика. Психологииеская диагоостика, 3, 3-21.

Мильман, В. Э. (2005). Мотивация твориества и роста. Структура. Диахностика. Развитие. М.: ООО «Мирея и Ко».

Петухова, И. А. (1976). Умственные способности как компонент интеллектуальной инициативы. Вопросы психологии, 4, 80-89.

Равен, Д. К. (2002). Продвинутые прогрессивные матрицы: Серии 1, 2. М.: Когито-Центр.

Рубинштейн, С. Л. (1960). Проблема способ́нстей и вопросы психологической теории. Boпросы психологии, 3, 3-8.

Шалриков, В. Д. (2006). Мир внутренней жизни человека. М.: Логос.

Шадриков, В. Д. (2010). Профессиональные способности. М.: Университетская книга.

Щебланова, Е. И., Щербо, Н. П., Шумакова, Н. Б. (1993). Фигурная форма теста твориеского мыиления П. Торренса. Методические рекомендации по работе с тестом. М.: Институт развития одаренности.

Якиманская, И. С. (2004). Психологищеские основы математимеского образования. М.: ИЦ «Академия».

Ссылки на зарубежные источники см. в разделе References после аналоязыиного блока.
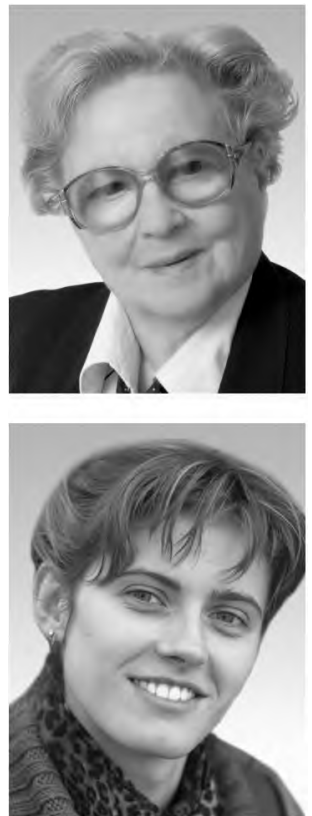

Богоявленская Диана Борисовна - главный научный сотрудник, ФГБНУ «Психологический институт $\mathrm{PAO}$, доктор психологических наук, профессор, почетный член РАО, академик МАПН, PAEH.

Сфера научных интересов: психология мышления, творчества и одаренности.

Контакты: mpo-120@mail.ru

Низовцова Анна Николаевна - аспирант, Московский государственный университет имени М.В. Ломоносова.

Сфера научных интересов: психология творчества и одаренности, математические способности.

Контакты: anna_nizovtsova@mail.ru 


\title{
On a Problem of Relationships of General, Special and Creative Abilities on Example of Mathematical Giftedness
}

\author{
D.B. Bogoyavlenskaya ${ }^{a}$, A.N. Nizovtsova ${ }^{b}$ \\ ${ }^{a}$ Psychological Institute of the Russian Academy of Education, 9/4 Mokhovaya str., Moscow, 125009, \\ Russian Federation \\ ${ }^{b}$ Lomonosov Moscow State University, 1 Leninskie Gory, Moscore, Russia, 119991, Russian Federation
}

\begin{abstract}
The article examines the problem of relationships between general, special and creative abilities. We analyzed theoretical views on the problem of general and special abilities and described the discussion between V.A. Krutetskii and S.L. Rubinstein. As the result, it was shown that special abilities are actually reduced to the general ones. The final solution of this problem was suggested by V.D. Shadrikov in his theory of abilities as the properties of the functional systems and special abilities as the general ones that acquired efficiency under the influence of the demands of activities; thus a contradiction is removed and the question of the nature of special abilities is answered. The problem of relationships between general and creative abilities is nowadays the most pressing abroad (B. Sriraman, D. Pitta-Pantazi, M. Kattou, R. Leikin, etc.). In some ways, V.D. Shadrikov problematizes it. He describes abilities at three levels - individual (natural abilities), the subject of activity (special abilities) and personality (including the moral field). Abilities on a personal level are considered as giftedness that can develop into creativity. Further we speak about creative abilities as the ability to develop activity on one's own initiative, which is the development of the process-activity approach by S.L. Rubinstein. We examine the relationship of different types of abilities by an example of mathematical giftedness. The participants were students and graduates in mathematics (including $\mathrm{PhD}$ ) from the best Russian universities $(\mathrm{n}=83)$. Creative abilities and giftedness were measured with mathematical material that was developed in the framework of "Creative Field". The results are compared with the intellectual and personal tests. It was shown that the general abilities provide the acquirement of mathematical material. The most important for creativity and giftedness is cognitive attitude, which is expressed in development of activities on one's own initiative.
\end{abstract}

Keywords: general abilities, special abilities, mathematical abilities, giftedness, creativity, personality.

\section{References}

Bogoyavlenskaya, D. B. (1971). Metod issledovaniya urovnei intellektual'noi aktivnosti [The study method of the levels of intellectual activity]. Voprosy Psikhologii, 1, 144-146.

Bogoyavlenskaya, D. B. (1983). Intellektual'naya aktionost' kak problema toorchestva [Intellectual activity as a problem of creativity]. Rostov on Don: Rostov State University.

Bogoyavlenskaya, D. B. (2002). Psikhologiya tvorcheskikh sposobnostei [The psychology of creative abilities]. Moscow: Akademiya. 
Bogoyavlenskaya, D. B. (2009). Psikhologiya tvorcheskikh sposobnostei [The psychology of creative abilities]. Samara: Publishing House "Fedorov".

Cipora, K., Hohol, M., Nuerk, H. C., Willmes, K., Brożek, B., Kucharzyk, B., \& Nęcka, E. (2016). Professional mathematicians differ from controls in their spatial-numerical associations. Psychological Research, 80(4), 710-726.

Demetriou, A., Christou, C., Spanoudis, G., \& Platsidou, M. (2002). The development of mental processing: efficiency, working memory, and thinking. Monographs of the Society for Research in Child Development, 67(1), i-viii, 1-155.

Goldberg, A., \& Suppes, P. (1972). A computer-assisted instruction program for exercises on finding axioms. Educational Studies in Mathematics, 4(4), 429-449.

Hadamard, J. (1970). Issledovanie psikhologii protsessa izobreteniya v oblasti matematiki [The psychology of invention in the mathematical field]. Moscow: Sovetskoe Radio. (Transl. of: Hadamard, J. (1959). Essaisur la psychologie delinventiondans le domaine mathumatique [The Psychology of Invention in the Mathematical Field]. Paris: Albert Blanchard. (in French))

Haylock, D. W. (1987). A framework for assessing mathematical creativity in school children. Educational Studies in Mathematics, 18(1), 59-74.

Hershkowitz, R. (1989). Visualization in geometry - two sides of the coin. Focus on Learning Problems in Mathematics, 11, 61-76.

Hong, E., \& Aqui, Y. (2004). Cognitive and motivational characteristics of adolescents gifted in mathematics: Comparisons among students with different types of giftedness. Gifted Child Quarterly, 48(3), 191-201.

Kattou, M., Kontoyianni, K., Pitta-Pantazi, D., \& Christou, C. (2013). Connecting mathematical creativity to mathematical ability. ZDM - Intemational Joumal on Mathematics Education, 45(2), 167-181.

Kiesswetter, K. (1985). Die Förderung von mathematisch besonders begabten und interessierten Schülern - ein bislang vernachlässigtes sonderpädagogisches Problem [The promotion of mathematically particularly talented and interested pupils - a so far neglected special educational problem]. Mathematisch-naturwissenschaftlicher Unterricht, 38(5), 300-306. (in German)

Kontoyianni, K., Kattou, M., Pitta-Pantazi, D., \& Christou, C. (2013). Integrating mathematical abilities and creativity in the assessment of mathematical giftedness. Psychological Test and Assessment Modeling, 55(3), 289-315.

Krutetskii, V. A. (1968). Psikhologiya matematicheskikh sposobnostei shkolnikov [The psychology of mathematical abilities of schoolchildren]. Moscow: Prosveshchenie.

Leikin, R., \& Pitta-Pantazi, D. (2013). Creativity and mathematics education: The state of the art. ZDM-International Journal on Mathematics Education, 45(2), 159-166.

Leontiev, D. A., \& Ilchenko, A. N. (2007). Urovni mirovozzrencheskoi aktivnosti i ikh diagnostika [The levels of worldview's activity and their diagnostics]. Psikhologicheskaya Diagnostika, 3, 3-21.

Mann, E. L. (2006). Creativity: The essence of mathematics. Joumal for the Education of the Gifted, 30(2), 236-260.

Milman, V. E. (2005). Motivatsiya tvorchestva i rosta. Struktura. Diagnostika. Razvitie [Motivation of creativity and growth: Structure. Diagnostics. Development]. Moscow: OOO “Mireya i Ko".

Petukhova, I. A. (1976). Umstvennye sposobnosti kak component intellektual'noi initsiativy [Intellectual abilities as a component of intellectual initiative]. Voprosy Psikhologii, 4, 80-89.

Pitta-Pantazi, D., Christou, C., Kontoyianni, K., \& Kattou, M. (2011). A model of mathematical giftedness: integrating natural, creative, and mathematical abilities. Canadian Joumal of Science, Mathematics and Technology Education, 11(1), 39-54. 
Pitta-Pantazi, D., Sophocleous, P., \& Christou, C. (2013). Spatial visualizers, object visualizers and verbalizers: their mathematical creative abilities. ZDM - Intemational Journal on Mathematics Education, 45(2), 199-213.

Raven, J. C. (2002). Prodvimutye progressiznye matritsy: Serii 1, 2 [Advanced Progressive Matrices: Series 1, 2]. Moscow: Kogito-Tsentr.

Rubinstein, S. L. (1960). Problema sposobnostei i voprosy psikhologicheskoi teorii [The problem of abilities and issues of psychological theory]. Voprosy Psikhologii, 3, 3-8.

Shadrikov, V. D. (2006). Mir vmutrennei zhizni cheloveka [The world of the inner life of a man]. Moscow: Logos.

Shadrikov, V. D. (2010). Professional'mye sposobnosti [Professional abilities]. Moscow: Universitetskaya Kniga.

Shcheblanova, E. I., Shcherbo, N. P., \& Shumakova, N. B. (1993). Figumaya forma testa tvorcheskogo myshleniya P. Torrensa. Metodicheskie rekomendatsii po rabote $s$ testom. [Figured form of the Torrance tests of creative thinking. Methodical recommendations for working with the test]. Moscow: Institut razvitiya odarennosti.

Singer, F. M., Sheffield, L. J., Freiman, V., \& Brandl, M. (2016). Research on and activities for mathematically gifted students. In F. M. Singer, L. J. Sheffield, V. Freiman, \& M. Brandl, Research on and activities for mathematically gifted students (pp. 1-41). Cham, Switzerland: Springer International Publishing AG.

Sriraman, B. (2003). Mathematical giftedness, problem solving, and the ability to formulate generalizations: The problem-solving experiences of four gifted students. Journal of Advanced Academics, 14(3), 151-165.

Sriraman, B. (2004). The characteristics of mathematical creativity. The Mathematics Educator, 14(1), $19-34$.

Sriraman, B. (2005). Are giftedness and creativity synonyms in mathematics? Joumal of Advanced Academics, 17(1), 20-36.

Sriraman, B., Haavold, P., \& Lee, K. (2013). Mathematical creativity and giftedness: a commentary on and review of theory, new operational views, and ways forward. ZDM-International Joumal on Mathematics Education, 45(2), 215-225.

Yakimanskaya, I. S. (2004). Psikhologicheskie osnorn matematicheskogo obrazovaniya [Psychological foundations of mathematical education]. Moscow: Akademiya.

Diana B. Bogoyavlenskaya - chief reasearch fellow, Psychological Institute of the Russian Academy of Education, D.Sc., professor, honorary fellow of the Russian Academy of Education, Member of the International Academy of Psychological Science.

Research area: psychology of thinking, creativity and giftedness.

E-mail: mpo-120@mail.ru

Anna N. Nizovtsova - post-graduate student, department of psychology, Lomonosov Moscow State University.

Research area: psychology of creativity and giftedness, mathematical abilities.

E-mail: anna_nizovtsova@mail.ru 